\title{
Paediatric palliative medicine
}

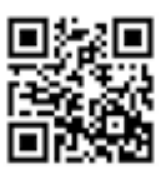

In November 2013, the International Children's Palliative Care Network (ICPCN), based in South Africa, and the United Nations Children's Fund (UNICEF) released a document entitled Assessment of the Need for Palliative Care for Children. Three Country Report: South Africa, Kenya and Zimbabwe. ${ }^{[1]}$ It reported that, even though an underestimate, $>800000$ children in South Africa were in need of generalised palliative care and $>300000$ in need of specialised palliative care. Moreover, it was estimated that only 5\% of children requiring specialised care were being reached. This low coverage was a result of 'inadequate inclusion of children's palliative care within policy and strategy frameworks; widespread lack of knowledge and adequate understanding among health professionals; narrow target focus of services being provided already; the reluctance of health workers to prescribe and/or administer morphine despite the availability of essential palliative care pharmaceutical agents, resulting in a major barrier for access to comprehensive pain management; funding constraints and attendant poor integration of palliative care into the health system. ${ }^{\text {[1] }}$

In South Africa, children's palliative care is still in its infancy, even though in many other countries palliative medicine and paediatric palliative medicine are recognised medical specialties. Adult palliative medicine came about in the 1960s through the initiative of Dame Cecily Saunders and the opening of St Christopher's Hospice in London. In 1982, the first children's hospice, Helen House in Oxford, was established, and since then attention has increasingly focused on the needs of children with life-limiting and life-threatening illnesses and their families. ${ }^{[2]}$ The World Health Organization (WHO) defined palliative medicine for the first time in 1990, with the children's definition being added in $1998{ }^{[3]}$ Initially, palliative medicine was defined as being accessed when curative care is no longer possible, but it is now widely accepted and understood that palliative medicine should be fully integrated into the care of any life-threatening and life-limiting illness. ${ }^{[4]}$ Recent consensus statements emphasising the growing understanding of the need to advocate strongly for palliative care integration into the continuum of care for all patients, came from the African Palliative Care Association Conference held in Johannesburg in September 2013. ${ }^{[5]}$ An international resolution encouraging all member states to take a greater interest in palliative care, including palliative care for children, was adopted by the WHO in January $2014,{ }^{[6]}$ and also by the 67th World Health Assembly in Geneva, Switzerland, in May 2014. ${ }^{[7]}$
Children's palliative care is unique, covering a wide spectrum of ages - from birth to at least 18 years and sometimes beyond. It is unique in that children's developmental needs, understanding and capabilities differ. They have distinct educational needs, and perceptions of illness, dying and death, which are influenced by their developmental stage, cultural and family traditions, and religion. Diseases of childhood are diverse and complex and often no longer seen in adults, as many congenital and childhood diseases severely constrain life expectancy. Furthermore, perinatal palliative medicine is becoming an area of growing importance, interest, research, training, and advocacy. Disease symptoms present differently in children, who cannot be treated as small adults. Assessment is specialised and requires knowledge of the stages of development, communication and care needs. Medication doses are complex, largely weight related, and side-effect profiles can differ from those of adults. This illustrates the need for a unique understanding of the palliative care needs of children affected by lifelimiting and life-threatening illnesses. Despite the necessity for special training and experience, non-specialists and palliative care specialists should work together as a team in the service of children and their families who require this type of care.

The articles in this edition of CME discuss the ethical aspects of end-of-life dilemmas in children, communication with children, counselling, breaking bad news, pain control, and self-care, and have been written by palliative care professionals currently working in paediatric palliative medicine in South Africa. There are few specialist services for children's palliative care in South Africa, and even fewer hospital-and community-based programmes that can rely on specialist knowledge. Therefore, the generalist doctor must have a working understanding of some children's palliative care issues. Even specialists may find these articles of interest, as there are limited training and educational opportunities for dissemination of this type of knowledge. (Available online resources for further reading and short courses are listed below.) There is still much work to be done. The authors and I hope that children's palliative care gains a much deserved place and acceptance in the area of policy development, resource allocation, educational opportunities and service provision in South Africa.

\section{WHO definition of palliative care for children $^{[3]}$}

Palliative care for children represents a special, albeit closely related, field of adult palliative care. The WHO definition of palliative care appropriate for children and their families is as follows: 
- Palliative care for children is the active total care of the child's body, mind and spirit, and also involves giving support to the family.

- Palliative care begins when illness is diagnosed, and continues regardless of whether or not a child receives treatment directed at the disease.

- Health providers must evaluate and alleviate a child's physical, psychological, and social distress.

- Effective palliative care requires a broad multidisciplinary approach that includes the family and uses available community resources; it can be successfully implemented even if resources are limited.

- Palliative care can be provided in tertiary care facilities, in community health centres and even in children's homes.

These principles also apply to other chronic paediatric disorders.

\section{Online resources and short courses}

- Palliative Treatment for Children (PATCH) South Africa is an inclusive and compassionate network that aims to share specialised knowledge, tools and opportunities to ensure the best possible care for children with life-threatening and life-limiting illnesses, and to provide support to families and lay caregivers. http://www.patchsa. org/\#about (accessed 3 June 2014).

- ICPCN raises awareness for children's palliative care through lobbying for global development, and sharing expertise, skills, and knowledge. It has online educational programmes. http://www. icpcn.org/ (accessed 3 June 2014).

- The Hospice Palliative Care Association of South Africa can assist with accessing a hospice organisation locally, regionally and nationally. http://www.hospicepalliativecaresa.co.za/ (accessed 3 June 2014).

- Umduduzi, a Durban-based children's palliative care service, provides palliative services to children and families in KwaZuluNatal and training in paediatric palliative care locally, nationally and internationally. http://www.umduduzi.co.za/ (accessed 3 June 2014; site temporarily under construction).
- Together for Short Lives is a prominent UK children's palliative care charity that supports families, professionals and services and has many online resources in palliative care pathways and policies. http://www.togetherforshortlives.org.uk/professionals (accessed 3 June 2014).

- The website for palliative care news, views and inspiration around the world is given here. The international children's Palliative Care News is hosted by ICPCN. http://www.ehospice.com/internationalchildrens/ en-gb/home.aspx (accessed 3 June 2014).

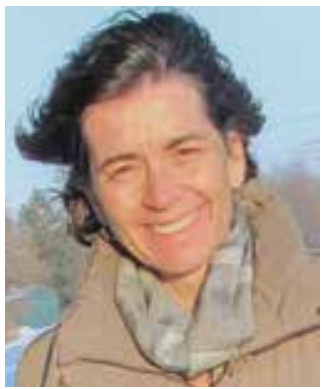

\section{Patricia Lück}

Guest editor

patricialuck@me.com

1. United Nations Children's Fund (UNICEF)/International Children’s Palliative Care Network (ICPCN). Assessment of the Need for Palliative Care for Children. Three Country Report: South Africa, Kenya and Zimbabwe. November 2013. New York: UNICEF/ICPCN, 2013. http://www.unicef.org/aids/files/ Palliative_Care_Three_Country_Report_Nov13.pdf (accessed 24 March 2014).

2. Baum D, Curtis H, Elston S, et al. A Guide to the Development of Children's Palliative Care Services. Bristol: ACT/RCPCH, 1997.

World Health Organization. The WHO definition of paediatric palliative care. http://www.who.int/ cancer/palliative/definition/en/ (accessed 24 March 2014).

Stjernswärd J, Foley KM, Ferris FD. The public health strategy for palliative care. J Pain Symptom Manage 2007;33:486.

African Palliative Care Association. Consensus statement for palliative care integration into the health system in Africa: Palliative Care for Africa. African Palliative Care Association Conference, Johannesburg, South Africa, 17 - 23 September 2013

orld Health Organization. Strengthening of Palliative Care as a Component of Integrated Treatment Within the Continuum of Care, 2014. http://www.thewpca.org/resources/resolution-to-strengthenpalliative-care/ (accessed 24 March 2014)

7. eHospice Palliative Care News. Adoption of resolution on palliative care at the 67th World Health Assembly Meeting, Geneva, Switzerland, 23 May 2014. http://www.ehospice.com/ArticleView/ tabid/10686/Articleld/10614/language/en-GB/View.aspx (accessed 3 June 2014).

S Afr Med J 2014;104(7):505-506. DOI:10.7196/SAMJ.8428 